\title{
Taurodont First Molar and its Treatment
}

\author{
Bilge Ozcan**1 ${ }^{1}$ Bade Sonat $^{2}$ \\ ${ }^{I}$ Turkish Ministry of Health Mamak Oral and Dental Health Center, Ankara, Turkey \\ ${ }^{2}$ Ankara University, Faculty of Dentistry, Department of Endodontics Ankara, Turkey \\ *Corresponding Author: Bilge OZCAN, Turkish Ministry of Health Mamak Oral and Dental Health \\ Center, Ankara, Turkey
}

\begin{abstract}
Morphological anomalies in the root and crown of the tooth are quite common. Taurodontism, one of the most important structural anomalies of the tooth, is a developmental anomaly associated with the anatomical structure of the tooth. In this study, taurodontism was found in the first and second molars of a 28-year-old female patient admitted to our clinic with pain complaints. Root canal treatment was applied on tooth number 46 and the pulp chamber was filled with MTA. The patient was followed up.
\end{abstract}

Keywords: taurodontism, developmental anomaly, structural anomaly, dental treatment

\section{INTRODUCTION}

Morphological anomalies in the root and crown of the tooth are quite common. Changes seen in the structural and dental tissues such as the number, size, shape and size of the teeth create dental anomalies. Taurodontism, one of the most important structural anomalies of the tooth, is a developmental anomaly associated with the anatomical structure of the tooth. Taurodontism is a dental anomaly characterized by vertical expansion of the pulp chambers, apical displacement of the pulp base and no narrowing at the enamel-cement junction level. Bifurcation or trifurcation is seen in the roots [1].This anomaly was first described by GorganovicKranber in 1908. It was described in 1913 by Sir Arthur Keith. Keith named these teeth taurodontism, which consists of tauros, which means bull in Greek, and odontos, which means teeth, as it resembles the teeth of four-legged ruminant animals [2]. A large number of taurodont teeth have been found in anthropological studies conducted on fossils that are regarded as the ancestors of modern man. For this reason, they evaluated taurodont teeth as specific to the first human [3,4]. In a study that put the frequency of tarudontism in prehistoric and historical periods, it was reported that taurodontism is a general feature that changes with the change of chewing habits in humans [5]. Its etiology is still unknown, but various theories about taurodontic root formation have been put forward [6,7]. It is thought that Her twigs epithelial root sheath diaphragm may be due to horizontal invagination error or growth delay in the transverse process $[8,9]$. This anomaly can be unilateral or bilateral, there is no gender discrimination. Although permanent teeth are more frequently affected, it is also seen in primary teeth, and the same can be seen in one or more teeth in the half jaw [2]. The classification made by Shaw in 1928 is widely used today. Shaw classified taurondotism according to the degree of displacement of the pulp base towards the apical. Accordingly, taurodontism; It is grouped under three headings as hypo-, meso- and hyper-taurodontism, and the pyramid form of the root canal is also included [10]. Taurodontism may cause some difficulties in endodontic, orthodontic and / or prosthetic treatment planning. It may cause difficulties in instrumentation and canal filling during endodontic treatment. The shifting of the furcation to the apical triad may complicate the extraction of the taurodont tooth [11].

\section{Case Report}

A 28-year-old female patient was referred as a dental anomaly case from her private practice to Ankara University Faculty of Dentistry Endodontics clinic with complaints of pain in her teeth. Panoramic and periapical $\mathrm{x}$-rays are taken from the patient and examined. As a result of the evaluation, taurodontism was found in all first molars. The patient's complaint area has been evaluated with priority. In clinical evaluation, amalgam restoration in the first molar tooth and caries in the distoocclusal tooth were found in the lower right region. 
Percussion, palpation and mobility was not encountered. No pathology was found in soft tissues. Dentine caries was found in tooth number 46 on periapical X-ray and no pathology was observed in the periapical tissue (Figure 1).

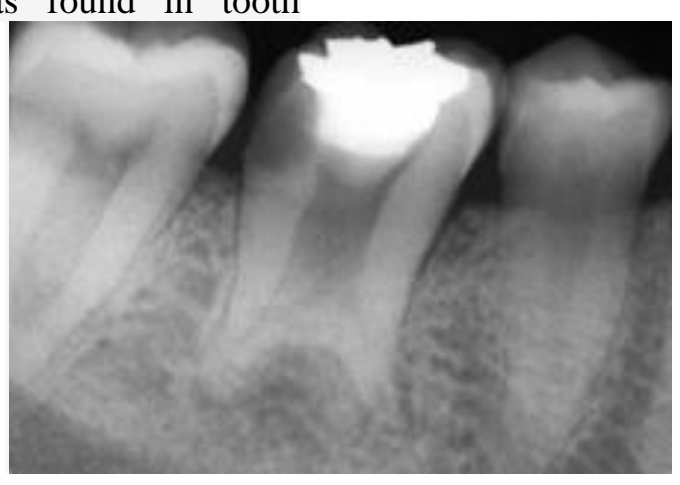

Figure1. Radiograph at diagnosis

Root canal treatment was indicated for the tooth with a diagnosis of irreversible pulpitis in the tooth whose clinical, radiological and patient history were listened, and treatment was started.

The first session with the patient to mandibular anesthesia (Ultraca D-SA, Aventis Pharma, Istanbul, Turkey), although we started as a result of hearing the patient's pain, in addition buccal infiltration anesthesia with deep intraligamentous- and intrapulpal anesthesia is provided. The old restoration was removed from the mouth, after opening the access cavity, a rubber-dam was applied. There are 4 channels, 2 in the mesial and 2 in the distal (Figure 2).

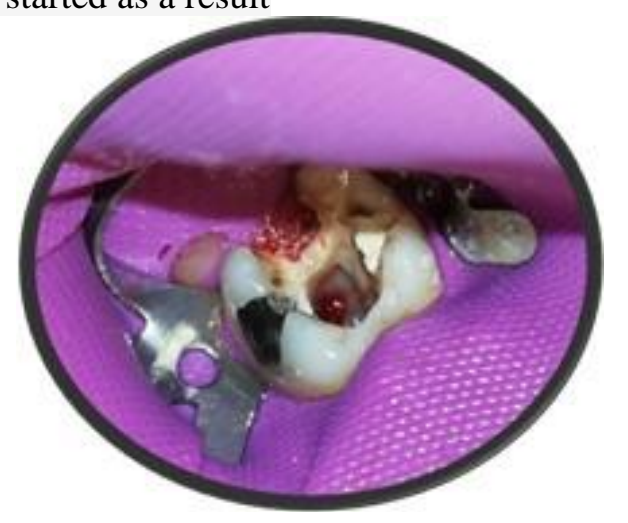

Figure2. Access cavityandrubber-dam application

Pulp chamber was extirpated with the help of excavator and canals tirnerf (Figure 3).

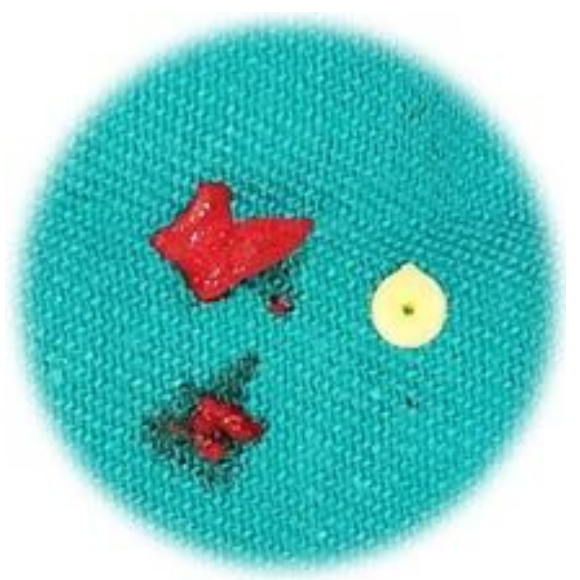

Figure3. Pulp extirpation

Pulp stone was removed from the pulp chamber. Then, K-type files were placed in the canals and the root canal length film was taken. The mesiobuccal tubercle was accepted as the reference and the mesial canals were measured as $18 \mathrm{~mm}$, and the distal canals as $17 \mathrm{~mm}$. Again, the distance from the reference point to the canal mouths was measured as $14 \mathrm{~mm}$ (Figure 4). 


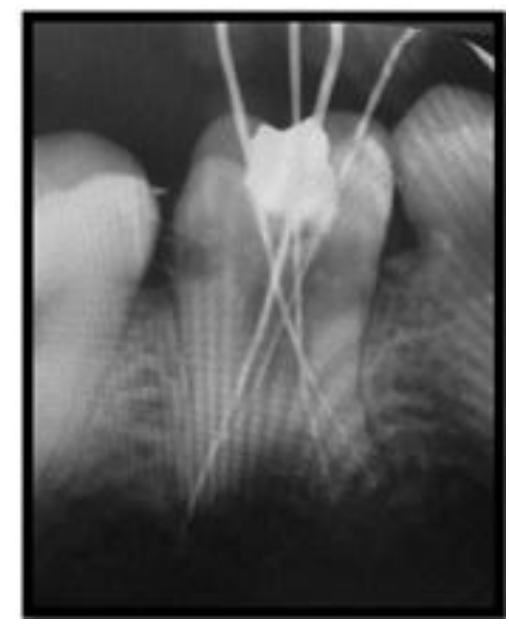

Figure4. Determination of working length

After the root canal lengths were determined, the channels were expanded up to S1, S2, F1 and F2 with the Pro Taper (Universal, Dentsply Maillefer. Switzerland) file system. $2 \mathrm{ml}$ of
$2.5 \% \mathrm{NaOCl}$ was used for irrigation at each file change. The last wash was done with saline solution and the root canals were filled with angled F2 gutta (Figure 5).

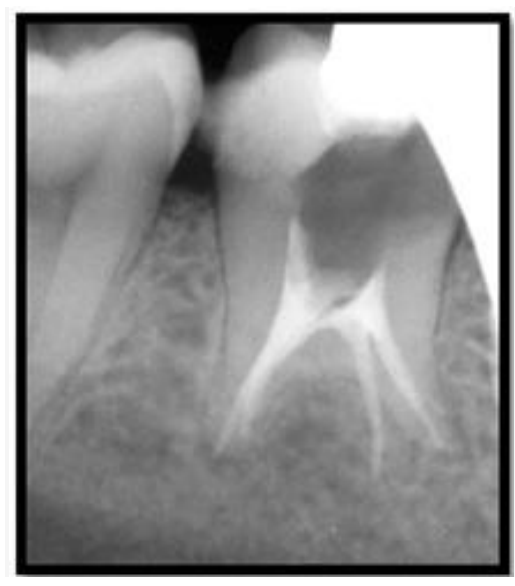

Figure5. Filling of root canals

Cotton pellets were placed on the gutt as cut from the canal mouths and the tooth was temporarily covered with glass ionomer cement. In the second session of the patient, the pulp chamber of $14 \mathrm{~mm}$ was filled with MTA Angelus and the coronal part of the tooth was restored with composite filling material (Figure 6).

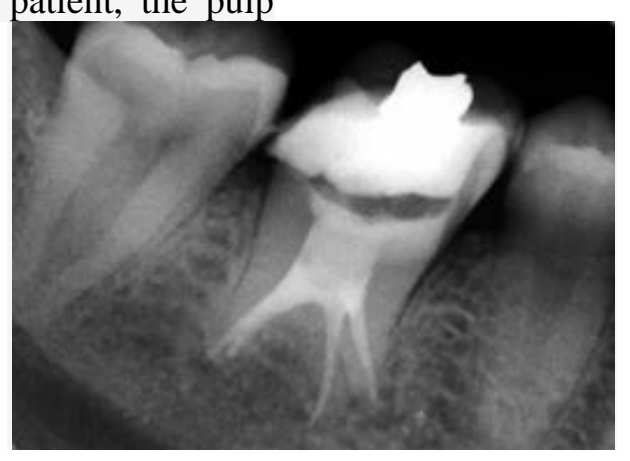

Figure6. Filling the remaining pulp chamber with MTA after root canal filling

\section{DISCUSSION}

Taurodontism appears to have a normal structure in human fossils belonging to the past in studies conducted in the 1908s. Therefore, the anatomical appearance in question is not an anomaly in human ancestors. It is a structural change that occurred during the evolutionary process [2]. Differences in the prevalence of taurodontism are considered to be social differences. It is more common in Eskimos, Israel, American Indians, a region of Spain and the Caucasus, suggesting that this anomaly is 
related to genetic and environmental factors $[4,9,11]$. This anomaly can be seen alone or together with many anomalies. Taurodont teeth can be seen together in chromosomal somatic disorders such as amelogenesis imperfecta, dentino genesis imperfecta, hypodontics, genetic disorders with systemic effects or Down syndrome [12-14].This anomaly is mostly seen in molar teeth. It can be seen unilaterally as well as bilaterally, and more than one tooth may be affected as in this case. In taurodont molar teeth, besides the width of the pulp chamber, there are also differences from the normal canal anatomy, and in this case, the treatment of these teeth becomes difficult.

Taurodontism can only be detected clinically by radiography. However, it has been suggested that measurement points may vary radiologically, and may be misleading due to insufficient root formation, root resorption and root tip displacement $[4,15]$.

In this study, it is thought that dentists who have anatomical knowledge and clinical experience can detect anatomical variations radio graphically, as in this case. The diagnosis and treatment of teeth with anatomical variations requires clinical training and experience. In this case, the pulp chamber was filled with MTA after the root canal filling was completed. In various studies, it is reported that MTA induces hard tissue formation. At the same time, MTA is defined as a material that can interact closely with osteoblast cells $[16,17]$. In many studies, it has been observed that the covering of MTA is quite superior compared to the compared materials [18-21]. In addition to its covering, expansion during erection is important in terms of preventing inter-tubular coronal leakage $[20,22,23]$. It is also antimicrobial and can be directly restored with composite without the need for a base material [24]. Considering its biological properties, it was applied to the tooth showing anatomical variation and the patient was followed.

\section{REFERENCES}

[1] Brkić H, Filipović I (1991) The meaning of taurodontism in oral surgery--case report. Acta Stomatol Croat 25(2): 123-127.

[2] Llamas R, Jimenez-Planas A (1993) Taurodontism in premolars. Oral Surg Oral Med Oral Pathol 75(4): 501-505.

[3] Ruprecht A, Batniji S, el-Neweihi E (1987) The incidence of taurodontism in dental patients. Oral Surg Oral Med Oral Pathol 63(6): 743-747.

[4] HAMNER JE 3rd, WITKOP CJ Jr, METRO PS (1964) TAURODONTISM; REPORT OF A
CASE.Oral Surg Oral Med Oral Pathol 18: 409-418.

[5] Pindborg JJ (1970) In: Pathology of the dental hard tissues. Copenhagen : Munksgaard, 1970. pp. $48-53$.

[6] Tsesis I, Shifman A, Kaufman AY (2003) Taurodontism: an endodontic challenge. Report of a case.J Endod 29(5) :353-355.

[7] Kulkarni G, Rajeev KG, Ambalavanan P, Kidiyoor KH (2012) Successful endodontic management of hypo, meso and hypertaurodontism: Two case reports.Contemp Clin Dent 3(Suppl 2): S253-256.

[8] Varrela J, Alvesalo L, Mayhall J (1973) Taurodontism in 45,X females.J Dent Res 69(2) : 494-495.

[9] Shaw JC (1928) Taurodont Teeth in South African Races.J Anat 62(Pt 4): 476-498.1.

[10] Bronoosh P, Haghnegahdar A, Dehbozorgi M (2012) Prevalence of taurodontism in premolars and molars in the South of iran.J Dent Res Dent Clin Dent Prospects 6(1): 21-24.

[11] Cichon JC, Pack RS (1985) Taurodontism: review of literature and report of case. J Am Dent Assoc 111(3): 453-455.

[12] Elzay RP, Chamberlain DH (1986) Differential diagnosis of enlarged dental pulp chambers: a case report of amelogenesis imperfecta with taurodontism. ASDC J Dent Child 53(5): 388390.

[13] Alpöz AR, Eronat C (1997) Taurodontism in children associated with trisomy 21 syndrome.J Clin Pediatr Dent 22(1): 37-39.

[14] Seow WK, Lai PY (1989) Association of taurodontism with hypodontia: a controlled study. Pediatr Dent 11(3): 214-219.

[15] MacDonald-Jankowski DS, Li TT (1993) Taurodontism in a young adult Chinese population. Dentomaxillo fac Radiol 22(3): 140144.

[16] Torabinejad M, Higa RK, McKendry DJ, Pitt Ford TR (1994) Dye leakage of four root end filling materials: effects of blood contamination. J Endod 20(4): 159-163.

[17] Mitchell PJ, Pitt Ford TR, Torabinejad M, McDonald F (1999) Osteoblast biocompatibility of mineral trioxide aggregate. Biomaterials 20(2): 167-173.

[18] Chong BS, Pitt Ford TR, Hudson MB (2003) A prospective clinical study of Mineral Trioxide Aggregate and IRM when used as root-end filling materials in endodontic surgery.Int Endod J 36(8): 520-526.

[19] Torabinejad M, Smith PW, Kettering JD, Pitt Ford TR (1995) Comparative investigation of marginal adaptation of mineral trioxide aggregate and other commonly used root-end filling materials.J Endod21(6):295-299. 
[20] Fischer EJ, Arens DE, Miller CH (1998) Bacterial leakage of mineral trioxide aggregate as compared with zinc-free amalgam, intermediate restorative material, and SuperEBA as a root-end filling material.J Endod 24 (3): 176-179.

[21] Fogel HM, Peikoff MD (2001) Microleakage of root-end filling materials. J Endod 27(7): 456458.

[22] Torabinejad M, Pitt Ford TR, McKendry DJ, Abedi HR, Miller DA, et al. (1997) Histologic assessment of mineral trioxide aggre gate as a root-end filling in monkeys. $\mathbf{J}$ Endod 23(4): 225-228.

[23] Nakata TT, Bae KS, Baumgartner JC (1998) Perforation repair comparing mineral trioxide aggregate and amalgam using an anaerobic bacterial leakage model. J Endod 24(3): 184186.

[24] Kim E, Jou YT (2000) A supernumerary tooth fused to the facial surface of a maxillary permanent central incisor: case report.J Endod 26(1): 45-48.

Citation: Bilge Ozcan \& Bade Sonat, “Taurodont First Molar and its Treatment”, International Journal of Research Studies in Medical and Health Sciences. 2021; 6(2): 9-13. DOI: https://doi.org/10.22259 /ijrsmhs. 0602002

Copyright: (C) 2021 Bilge Ozcan \& Bade Sonat, This is an open-access article distributed under the terms of the Creative Commons Attribution License, which permits unrestricted use, distribution, and reproduction in any medium, provided the original author and source are credited. 